\title{
A IMPORTÂNCIA DE UM PROFISSIONAL EM PORTFÓLIO: MÚLTIPLAS FORMAÇÕES COM VISTAS À GESTÃO DE CRISES PROFISSIONAIS, EMPRESARIAIS E GOVERNAMENTAIS DURANTE A PANDEMIA
}

\author{
Gabriela Maia ${ }^{1}$
}

\begin{abstract}
RESUMO: Este artigo objetiva pesquisar até que ponto um profissional em portifólio e com múltiplas formações se mostra de fato capacitado a gerir as crises profissionais, empresariais e governamentais que emergiram durante a citada pandemia. Para tanto, explica a gestão de competências individuais e gerenciais; analisa os Programas de Treinamento e Desenvolvimento, buscando estabelecer, com base na literatura, se os talentos podem ou não ser ensinados; e expõe as especificidades de uma liderança focada nas competências, multitalentos, forças e virtudes. No que concerne à metodologia, esta foi uma pesquisa bibliográfica, a qual consiste em analisar dados que foram coletados em outros estudos já publicados visando conhecer o que há de mais recente sobre o tema e auxiliando a encontrar respostas para o problema de pesquisa proposto. Concluiu-se ao final do estudo que os funcionários multiqualificados, também denominados de polivalentes ou multitalentos terão importante função na gestão das crises profissionais, empresariais e governamentais durante a pandemia da Covid-ı́ tendo em vista que terão sua produtividade majorada, além de estarem em condições de fornecer resultados de melhor qualidade à empresa e por serem uma força de trabalho flexível e adaptável.
\end{abstract}

Palavras-chave: Pandemia. Gestão de crises. Multicompetências. Polivalência.

ABSTRACT: This article aims to research the extent to which a professional in a portfolio and with multiple training is actually able to manage the professional, business and governmental crises that emerged during the aforementioned pandemic. To this end, it explains the management of individual and managerial competences; analyzes Training and Development Programs, seeking to establish, based on the literature, whether or not talents can be taught; and exposes the specifics of a leadership focused on competencies, multi-talent, strengths and virtues. Regarding the methodology, this was a bibliographic research, which consists of analyzing data that were collected in other studies already published in order to know what is most recent on the subject and helping to find answers to the proposed research problem. It was concluded at the end of the study that multi-skilled employees, also called multi-skilled or multi-talented, will play an important role in the management of professional, business and governmental crises during the Covid-I9 pandemic, given that their productivity will increase, in addition to being in able to deliver better quality results to the company and for being a flexible and adaptable workforce.

Keywords: Pandemic. Crisis management. Multi-skills. Multipurpose

\footnotetext{
I Advogada inscrita na OAB e no International Bar Association (IBA). Especialista em Direito Público, Internacional, Tributário, Digital, Penal e Processual Penal, Marítimo, Médico e Hospitalar. LLM em Direito dos Contratos e MBAs Executivos nas Áreas de Negócios Internacionais e Comércio Exterior, Controladoria e Finanças, Gerenciamento Executivo de Projetos, Petróleo e Gás, Gestão de Pessoas e Recursos Humanos, Marketing e Redes Sociais e Gestão Competitiva e Business Intelligence (BI). Pedagoga Especializada em Psicopedagogia, Neurociência e Comunicação em Ambientes Corporativos e Neuropsicopedagogia Institucional, Clínica e Hospitalar. https://orcid.org/oooo-ooor-9822-4122. Email:gabrielamaia78@hotmail.com.
} 


\section{INTRODUÇÃO}

Hodiernamente, a partir da crise pandêmica que assolou o mundo, não somente as empresas, mas também as pessoas e os governantes têm enfrentado desafios de natureza distinta que, com o passar dos tempos, naturalmente perseguem a tendência de se renovarem e operarem mudanças. Dessa forma, o mercado se mostra um contexto de elevada competitividade, onde as empresas que estão preparadas para enfrentar as adversidades passam a ter maiores chances não apenas de crescer, mas, também de se manter no mercado. No entanto, isto não é uma novidade. A competição em si sempre existiu e, com o passar dos tempos, o que se observa é que em situações onde as pessoas enfrentam desafios é que surgem as oportunidades de crescimento.

Além do movimento e da constante adaptação que pode ou não ser um fator ocasionado pela competitividade, as empresas, sejam elas públicas ou privadas, ainda precisam saber lidar com o desconhecido. Zarifian (2008) colabora para o melhor entendimento desta situação, fornecendo o conceito de eventos, que em seu conceito, "são situações imprevistas, inusitadas, que podem perturbar a normalidade do sistema produtivo” (ZARIFIAN, 20o8, p.7). No entanto, são os muitos desafios colocados pelo mercado, como, por exemplo, a grande competitividade em nível global, a grande redução do ciclo de vida de produtos e também dos serviços, o desenvolvimento tecnológico, a crise pandêmica decorrente da Covid-ıg e que a seu turno, fez surgir muitas outras crises, como a crise econômica e a crise existencial.

Mesmo antes da pandemia da Covid-19, as mudanças nas tecnologias e as novas formas de trabalho estavam levando à perda de empregos tendo em vista a dificuldade de encontrar funcionários com as habilidades demandadas pelo mercado. Em 2017, o McKinsey Global Institute estimou que cerca de 375 milhões de trabalhadores o que representa cerca de I4\% da força de trabalho global - teriam que mudar de ocupação ou adquirir novas habilidades até 2030 em razão da crescente automação e inteligência artificial (MCKINSEY GLOBAL INSTITUTE, 20I7). Também, em uma pesquisa global mais recente, também da McKinsey, 87\% dos executivos disseram estar enfrentando lacunas de habilidades na força de trabalho ou as esperavam dentro de alguns anos. No entanto, menos da metade dos entrevistados tinha uma noção clara de como poderiam solucionar o problema (MCKINSEY GLOBAL INSTITUTE, 2020). 
A pandemia de coronavírus tornou essa questão mais urgente. Trabalhadores de todos os setores estão tendo que descobrir como podem se adaptar às condições em rápida mudança, e as empresas precisam aprender como adequar esses trabalhadores às novas funções e atividades. Essa dinâmica é mais do que trabalho remoto - ou simplesmente resultado da automação e desenvolvimento exponencial da Inteligência Artificial (IA). É sobre como os líderes podem se requalificar e aprimorar a força de trabalho sob sua liderança, de modo a tornar estes profissionais polivalentes, multicompetentes e capazes de responder com equilíbrio às adversidades, para no futuro, quem sabe, oferecer os novos modelos de negócios que surgiram na era pós-pandemia.

Apresentados estes delineamentos iniciais, o problema norteador desta pesquisa foi: em que medida um profissional em portifólio e com múltiplas formações se mostra de fato capacitado a gerir as crises profissionais, empresariais e governamentais durante a Covid19?

Visando responder ao questionamento proposto, este artigo tem como objetivo geral pesquisar até que ponto um profissional em portifólio e com múltiplas formações se mostra de fato capacitado a gerir as crises profissionais, empresariais e governamentais que emergiram durante a citada pandemia.

Para atingi-lo, os seguintes objetivos específicos foram delineados: explicar a gestão de competências individuais e gerenciais; analisar os Programas de Treinamento e Desenvolvimento, buscando estabelecer, com base na literatura, se os talentos podem ou não ser ensinados; e expor as especificidades de uma liderança focada nas competências, multitalentos, forças e virtudes.

Trata-se de um tema importante não apenas por sua atualidade, mas, por desnudar os crescentes desafios impostos aos governos em âmbito mundial, população civil, empresários e governos que não obstante não se neguem a enfrentar esse desafio, não sabem como fazê-lo para responder às demandas de um mercado cada vez mais dinâmico, competitivo e especializado.

Assim, talvez o caminho mais simples e viável seja o de que as empresas elaborem uma estratégia de talentos que desenvolva as capacidades digitais e cognitivas críticas dos funcionários, suashabilidades sociais e emocionaise sua adaptabilidade e resiliência. Agora é o momento que as empresas têm para dobrarem seus orçamentos de 
aprendizado e se comprometerem com a requalificação, saindo ainda mais fortalecidas para futuras disrupções.

Por fim, no que concerne à metodologia empregada no desenvolvimento deste artigo, esta foi pesquisa bibliográfica, a qual consiste em analisar dados que foram coletados em outros estudos já publicados visando conhecer o que há de mais recente sobre o tema.

Findas estas considerações introdutórias, analisa-se na próxima seção a gestão de competências individuais e gerenciais.

\section{GESTÃO DE COMPETÊNCIAS}

Brandão e Carbone (2006, p.43) apresentam a competência humana como "Combinações sinergéticas de conhecimento, habilidades e atitudes, expressas pelo desempenho profissional dentro de determinado contexto organizacional, que agregam valor a pessoas e organizações"

Autores como Kaplan e Norton (2006) e Dutra (2007), dentre outros, discutem o alinhamento da estratégia atualmente em vigor com as competências organizacionais necessárias para cumpri-la e executá-la, inferindo que o principal "recurso" que possibilita a continuidade e a competitividade das organizações é o investimento em desenvolvimento e gestão de competências organizacionais e individuais, estas últimas, a seu turno, também alinhadas às demais estratégias já propostas e vice-versa. Ou seja, não basta às organizações conhecerem suas competências, também é imprescindível que as desenvolvam alinhadas à orientação estratégica adotada.

Boterf (2003) e Zarifian (2008) destacam que um aspecto importante para o avanço no entendimento dessa abordagem conceitual é a correta distinção entre o que é qualificação e o que é competência. Para os autores, qualificação refere-se aos recursos (conhecimentos, habilidades e comportamentos) e competência refere-se ao modo como esses recursos são utilizados. Assim, tem-se que enquanto prevaleceu os modelos taylorista e fordista de organização do ambiente de trabalho e de estabelecimento de estratégias organizacionais, a ideia de qualificação viabilizou o referencial necessário para se trabalhar de forma mais consistente a relação profissional indivíduo-organização.

Porém, a compreensão do termo competência passou a demonstrar um desajuste em atender às necessidades de empresas ao mesmo tempo complexas, mutáveis e inseridas em 
um mercado global, tendo em vista que somente estabelecer um conjunto de recursos individuais necessários para que cada cargo ou função obtenham um bom desempenho não é o bastante para atender à constante demanda por inovação e flexibilidade impostas às organizações (RUAS, 2005), especialmente no cenário atual.

Segundo Dutra (2007), é fundamental o entendimento de que somente através da execução de atividades profissionais orientadas à luz das diretrizes estratégicas provenientes da missão e visão da empresa, o indivíduo, ou o grupo, estará convertendo suas capacidades e qualificações em competências. Dentro deste sentido lógico, nasce o fundamento básico da noção de competência: o conceito de entrega, que, em última análise, é o cumprimento de uma função estratégica por meio de uma ação alinhada com os objetivos da empresa.

No mesmo sentido Munck e Borim-de-Souza (2008) explicam que as competências aproximam homens e empresas valendo-se de uma compreensão contributiva e sistemática, na qual cada uma destas personagens responde por um compromisso social conjunto, em que todos exercem suas funções em processos de desenvolvimento ancorados em premissas responsáveis. Assim, para os autores, existe uma valorização do ser humano como agente de mudanças e das organizações na medida em que podem ser ambientes para recepção, tratamento e transferência destas revoluções.

Ao perpassar da competência individual para a organizacional, introduz-se a noção de empresa como "um portfólio de competências" (FLEURY; FLEURY, 2004, p. 32).

As empresas precisam desenvolver competências necessárias para seu funcionamento, estratégias, distinção no mercado, além de conseguir promover as competências individuais que sejam capazes de agregar valor à sua atividade e, também, valor social ao indivíduo. Assim, evidencia-se que a sustentabilidade empresarial pode ser desenvolvida por meio das competências individuais sob a ótica do saber agir, assumir responsabilidades e ter boas iniciativas.

\section{I.I Competências Individuais e Gerenciais}

Godoy (2008) identificou a competência individual como um conjunto de conhecimentos, habilidades, aptidões ou características relacionadas à alta performance na organização, como a capacidade de solucionar problemas, pensamento analítico ou talento para a liderança. 
As competências individuais estão relacionadas ao autodesenvolvimento. $O$ autodesenvolvimento, a seu turno, é um processo de evolução profissional dirigido pelo próprio colaborador. Entretanto, é necessário que este esteja disposto e preparado para assumir tal responsabilidade. É de suma importância que a empresa incentive e reconheça essa atitude, pois a falta de reconhecimento pode levar à perda de talentos fundamentais para o crescimento sustentado da empresa.

Segundo Senge (1997), as pessoas desenvolvem competências e por meio delas, tomam ciência de sua realidade, gerando conhecimento, que por sua vez influencia, estimula, inibe ou desenvolve atitudes e novas crenças. Ele relaciona o desenvolvimento das pessoas ao desempenho da empresa e troca vivências e aprendizado para que colaborador assuma seu papel criativo e contribua para o sucesso da organização sem se sentir explorado ou fadigado.

Nesse sentido, pode-se afirmar que o desenvolvimento de competências individuais é pré-requisito para que sejam desenvolvidas as competências organizacionais. A figura I apresentada a seguir ilustra os níveis de competências.

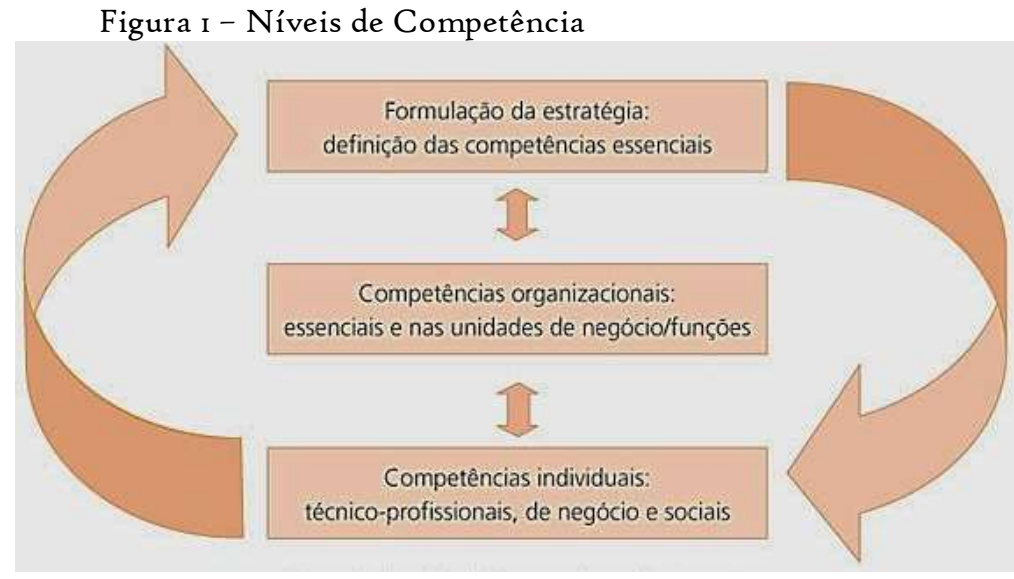

Fonte: Fleury e Lacombe (2003)

Complementarmente e considerando a grande demanda por competências, Sant'Anna (2009) atenta para a necessidade de enfatizar as competências diretamente associadas à performance das organizações, como a capacidade de gerar resultados e fazer com que os colaboradores se comprometam com os resultados das empresas nas quais trabalham. São as competências organizacionais.

Prahalad e Hamel (2005) introduzem o conceito de competência essencial, habilidades coletivas de aprendizagem ou competências organizacionais, que criam vantagem competitiva sustentável na cadeia de valor da empresa, diferenciando-a 
principalmente na sua capacidade de inovar em produtos e/ou serviços. Eles consideram as competências como as raízes da competitividade dos negócios e utilizam a metáfora da árvore para explicar a dinâmica organizacional, onde tais raízes estão relacionadas ao conjunto de competências, enquanto as folhas, flores e frutos estão vinculados aos produtos e/ou serviços finais, conforme ilustrado na figura 2 a seguir.

Figura 2. Competências como raízes da competitividade

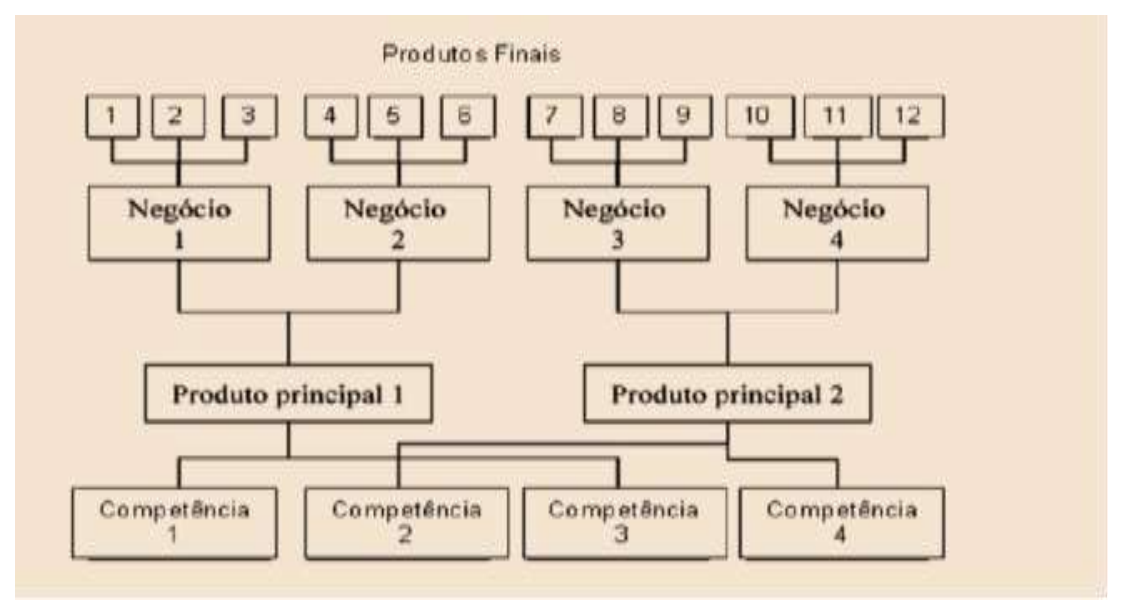

Fonte: Prahalad e Hamel (2005)

Para identificar as competências essenciais da organização os autores afirmam que é possível identificá-las por meio das seguintes questões-chave: a) O negócio é sustentável sem desenvolver estas competências? b) O que a empresa tem a perder se não desenvolver tais competências? c) Estas competências podem abrir novos mercados? d) Que benefícios efetivos os clientes percebem nestas competências? (PRAHALAD; HAMEL, 2005).

Enfim, a conjuntura atual tem colocado à prova a capacidade das empresas de se adaptarem rapidamente às mudanças nos seus ambientes de negócio. Para sobreviverem $e$ terem sucesso sustentado, as empresas precisam criar produtos e/ou serviços na medida exata das necessidades dos seus clientes, à frente inclusive do que eles imaginam. Um diferencial competitivo importante pode ser o desenvolvimento de uma visão de longo prazo que gere valor para o negócio, lastreada no desenvolvimento de competências para lançar produtos e/ou serviços inovadores mais rápido que os concorrentes.

A seu turno, este conjunto de competências gerenciais constitui o fator crítico de sucesso para a diferenciação das empresas no mercado, gerando a necessidade de um modelo de gestão estratégica de Recursos Humanos. 
A maioria das estratégias empresariais procura enfatizar o desenvolvimento dos seus talentos. Assim, as empresas ficam mais atentas às tendências do mercado, para desenvolver competências de modo a assegurar o sucesso sustentado do negócio em longo prazo (SANT'ANNA, 2009).

$\mathrm{Na}$ verdade, não há um processo de desenvolvimento de competências que possa ser considerado ideal. As pessoas não são iguais à medida que têm conhecimentos, habilidades e atitudes diferentes. Da mesma forma, é preciso que as diferentes culturas organizacionais sejam respeitadas, sendo que o grande desafio é a calibragem constante do modelo de competências às suas realidades. É neste contexto que entram os Programas de Treinamento e Desenvolvimento de Pessoas, que serão abordados na próxima seção.

\section{PROGRAMAS DE TREINAMENTO E DESENVOLVIMENTO: OS TALENTOS PODEM SER ENSINADOS?}

Geralmente, indivíduos que têm a pretensão de exercer cargos de liderança ou de gerência buscam por programas de formação gerencial com a expectativa de neles encontrar diferenciais que possam lhes auxiliar a lidar com os constantes desafios de suas carreiras, preparando-os para atuar em um mercado marcado pela instabilidade. Para os demais profissionais a motivação para se inscreverem em cursos desta natureza significa uma oportunidade de crescer em uma determinada organização, mudando de departamento, função ou, até mesmo, obtendo aumento em seus salários. Outros procuram se especializar em uma determinada matéria que não dominam muito bem. Ainda, existem aqueles para quem os programas de formação gerencial são um incentivo para se prepararem para procurar por um novo emprego. E, mesmo que não percebam, nesses cursos, os profissionais adquirem e desenvolvem conhecimentos, habilidades e atitudes, tornando possível explorar a aprendizagem de competências individuais.

No entanto, esta não é uma questão pacífica. Há quem defenda que os talentos são inatos e não podem ser ensinados. Segundo Paul Sills, citado no artigo de Kate Mcclanaghan (2019), todo mundo tem talentos, no entanto, segundo o autor, os talentos são como músculos e precisam ser exercitados, pois, caso contrário, irão atrofiar. Já as habilidades, estas podem e devem ser ensinadas e é a exposição dos colaboradores a uma diversidade de conteúdos e disciplinas que eleva as chances de se ter colaboradores polivalentes e capazes a tomar decisões em distintos cenários. 
Esta demanda por colaboradores polivalentes, os chamados colaboradores portifólios está cada vez mais em evidência, especialmente após as mudanças que se processaram no mercado de trabalho a partir da pandemia da Covid-ı9, tendo em vista que uma onda de automação e tecnologia digital derrubou a força de trabalho, destruiu alguns empregos e alterou como e onde o trabalho é exercido para quase todos.

Nos EUA, em 2020, um grupo formado por executivos e educadores corporativos que assessoravam o governo de Donald Trump sobre política de força de trabalho solicitou que o Governo investisse em caráter de urgência e em proporções sem precedentes nos trabalhadores americanos, tanto para fins de treinamento como para fins de qualificação visando à busca por empregos. Neste país, mesmo antes da pandemia, o ex-vice-presidente Joseph R. Biden Jr. propôs que fossem investidos US $\$$ so bilhões em treinamento da força de trabalho americana. Também no Congresso houve apoio de ambos os partidos (democratas e republicanos) para que os trabalhadores desempregados recebessem treinamento e para esta finalidade US $\$ 4.000$ foram disponibilizados. Na sequência, a Fundação Markle também se antecipou e propôs a abertura de "contas de oportunidade" financiadas pelo Governo Federal nas quais deveria ser depositado até US\$15.00o para os trabalhadores pudesse gastar em cursos de treinamento e qualificação. Por fim e não menos importante, os líderes sindicais ajudaram o governo a expandir os programas federais de aprendizagem para um número maior de indústrias (LOHR, 2020).

Mesmo com todas essas iniciativas, os EUA sentiram e estão sentindo o impacto da crise que assolou o mundo do trabalho. As consequências para este país têm sido duras e preocupantes. No Brasil, o quadro inspira ainda mais preocupação, pois não houve investimento em nenhum tipo de política pública para qualificar os trabalhadores, preparando-os para enfrentar o atual momento, em que a automação passou a dominar praticamente todas as atividades produtivas.

$\mathrm{Na}$ economia do coronavírus, as empresas já estão investindo em mais automação e para tanto, buscam reduzir os custos e elevar a eficiência. São recorrentes os debates sobre quais empregos correm maiores riscos de desaparecerem e em quanto tempo isto ocorrerá. Não se tendo a resposta para estes questionamentos, subir a escada das habilidades, competências e talentos parece ser a melhor forma de se proteger dos efeitos da automação, pois daqui em diante, ao que tudo indica, cada vez mais só sobreviverão no mercado de 
trabalho aqueles que tiverem se preparado para atuar em um mercado cada vez mais dependente das Tecnologias da Informação e Comunicação (TICs).

\section{DA IMPORTÂNCIA DOS PROFISSIONAIS MULTITALENTOS EM PERÍODOS DE CRISES}

$\mathrm{Na}$ configuração atual, onde os empregos são perdidos ou escassos devido à pandemia, aqueles que possuem várias habilidades conseguirão as posições desejadas. Em um sentido real de trabalho, a multiqualidade é um talento que pode ser benéfico no local de trabalho e valioso tanto para o empregado quanto para o empregador, especialmente em organizações modernas de ritmo acelerado, onde a filosofia não é mais a que incentiva concentrar-se apenas no próprio trabalho e nas próprias tarefas. Trata-se também de agregar valor a outras funções e habilidades. Portanto, os funcionários polivalentes possuem competências que lhes permitem atuar em áreas e departamentos além daqueles que já atuam (TERRA, 202I).

Essa flexibilidade é uma força de grande importância para uma empresa, pois os funcionários aprendem a se tornar flexíveis e responsivos às necessidades de negócios.

Organizações que sabem o que querem conhecem a necessidade de desenvolverem em seus recursos humanos oportunidades de aprendizagem, reconhecimento e participação nas decisões da empresa, o que viabiliza o bom relacionamento entre os colaboradores, tornando possível o trabalho em equipe. O momento é, pois, de investir em treinamento, qualificação, desenvolvimento de talentos e liderança de alta performance.

Liderança de alta performance é um programa projetado para ajudar os gerentes que são novos em sua posição de liderança, bem como aqueles com anos de experiência. $O$ programa permite que seus gerentes desenvolvam novas habilidades de liderança para ajudá-los a se tornarem mais eficientes no trabalho com funcionários, colegas e gerentes seniores (TERRA, 202I).

No Programa, os participantes aprendem como: conhecer suas responsabilidades de liderança de forma mais eficaz; estabelecer metas, remover obstáculos e identificar soluções alternativas para os principais desafios; comunicar-se de maneira mais produtiva com indivíduos, grupos e em toda a organização; liderar equipes de trabalho com mais sucesso; fornecer feedbacks que promovam aprendizado e mudança positiva; aplicar técnicas de gerenciamento de mudanças quando necessário; usar as habilidades de 
influência com sabedoria; e aplicar diretrizes de tomada de decisão para melhores resultados. Trata-se de liderança que transforma e promove o engajamento (COELHO; SOUSA, 2021).

Como os líderes transformacionais fornecem feedback construtivo aos seus seguidores, encorajando-os a pensar criativamente sobre problemas e mostrando ser capazes de convencê-los a se dedicarem cada vez mais, os próprios subordinados se beneficiam dessa influência e alcançam com maior facilidade níveis mais elevados de desempenho formal. O crescimento recente que levou ao desenvolvimento econômico no Brasil associado a uma preferência cultural por flexibilidade e criatividade deve apenas incentivar a abertura a estilos transformacionais (TERRA, 202I).

Os estudiosos têm articulado várias proposições sobre elementos capacitantes (isto é, elementos que intensificam a autoeficácia) na gama de comportamentos associados à liderança transformacional. Por exemplo, ao demonstrar determinação e otimismo, os líderes transformacionais podem inspirar autoconfiança em seus subordinados. Ações como delegação de funções, promoção da autonomia e estímulo à criatividade também podem estar diretamente relacionadas aos mecanismos sociais que fomentam a autoeficácia (DYER et al., 2017).

O líder transformacional também investe em uma motivação inspiradora que refere-se à capacidade do líder de inspirar confiança, motivação e um senso de propósito em seus seguidores. Assim, deve articular uma visão clara para o futuro, comunicar as expectativas do grupo e demonstrar um compromisso com as metas estabelecidas. Esse aspecto da liderança transformacional exige excelentes habilidades de comunicação, pois o líder deve transmitir suas mensagens com precisão, poder e senso de autoridade. Outros comportamentos importantes do líder incluem seu otimismo continuado, entusiasmo e capacidade de apontar o desempenho positivo (COELHO; SOUSA, 2021).

O sentido de direção inovadora que o líder transformacional fornece aos subordinados facilita a flexibilidade no processamento de informações, quebra de quadros cognitivos e perceptivos e usa categorias sociais amplas e inclusivas e, portanto, aumenta a identificação cognitiva com a organização (ou seja, percepções de similaridade entre membros da organização). No que diz respeito à identificação afetiva, os líderes transformacionais são capazes de inspirar os membros da organização, fornecendo 
significado e desafio ao seu trabalho, e envolvê-los emocionalmente com a visão que eles comunicam ao grupo (XENIKOU, 2017).

As implicações práticas dessas descobertas envolvem as diferentes estratégias que as organizações podem desenvolver para fortalecer seus laços com seus colaboradores, o que, por sua vez, pode ter um impacto positivo para os colaboradores e empresas em que atuam (DYER et al., 2017).

Por fim, ressalte-se que em um cenário, onde os valores devem ser constantes mesmo em um mundo em que todo o resto muda, havendo necessidade de busca contínua de qualidade do produto e satisfação dos clientes; de que gerentes se tornem líderes; de autonomia e responsabilidade profissional; e de desenvolvimento de equipes de alta performance.

É importante também que todas as lideranças foquem nas competências, nos multitalentos, nas forças e nas virtudes, pois, todas essas especificidades corroboram para a formação de equipes de alto desempenho.

\section{CONCLUSÃO}

Este artigo objetivou pesquisar até que ponto um profissional em portifólio e com múltiplas formações se mostra de fato capacitado a gerir as crises profissionais, empresariais e governamentais que emergiram durante a citada pandemia.

Foi visto que nas últimas duas décadas, passou-se a argumentar com maior frequência que os requisitos relacionados às habilidades estão sendo transformados como resultado de mudanças fundamentais que ocorreram na organização da produção. $O$ conceito-chave a este respeito tem sido o de flexibilidade e a utilização flexível do trabalho é vista como um elemento crucial das organizações de trabalho de alto desempenho que apoiam a produção de bens e serviços de alto valor agregado.

Alega-se que a produção deve ser organizada em torno de trabalhadores com amplas habilidades, engajados no trabalho em equipe e assumindo a responsabilidade pela qualidade do produto e melhoria contínua. Nesse sentido, a multiqualidade e a polivalência são benéficas para os funcionários, pois criam maiores oportunidades de trabalho, colaboração e flexibilidade. Ademais, haverá amplo interesse por parte dos empregadores em reter estes colaboradores devido às suas habilidades variadas. 
A seu turno, os colaboradores terão uma compreensão mais profunda do negócio, o que permite melhores perspectivas de crescimento e desenvolvimento das suas competências. Por derradeiro, as multicompetências também são benéficas para a organização, pois, as empresas terão mais liberdade no desenvolvimento de seus funcionários, já que estes, por serem polivalentes, poderão atuar em diversos projetos e departamentos, conforme necessidade.

Do exposto é possível concluir que os funcionários multiqualificados, também denominados de polivalentes ou multitalentos terão importante função na gestão das crises profissionais, empresariais e governamentais durante a pandemia da Covid-I9 tendo em vista que terão sua produtividade majorada, além de estarem em condições de fornecer resultados de melhor qualidade à empresa e de serem uma força de trabalho flexível e adaptável.

Assim, ficou clara a importância das pessoas nas organizações bem como a necessidade de empreender esforços para desenvolver competências e manter os colaboradores motivados, auxiliando no desenvolvimento de suas competências individuais e, adicionalmente, contribuindo para um ambiente profissional produtivo e de trabalho coletivo harmonioso.

\section{REFERÊNCIAS}

BOTERF, G. Desenvolvendo a competência dos profissionais. Porto Alegre: Artmed, 2003.

BRANDÃO, Hugo Pena. CARBONE, Pedro Paulo. Gestão por Competência e Gestão do Conhecimento. Rio de Janeiro: FGV, 2006.

COELHO, F. C. A.; SOUSA, R. B. Equipes de alta performance e o papel do líder para sua construção e desenvolvimento. Research, Society and Development, v. Io, n. 3, p. I-9, 202I.

DUTRA, J.S. Competências: conceitos e instrumentos para a gestão de pessoas na empresa moderna. São Paulo: Atlas, 2007.

DYER, W. G.; DYER, W. G. J.; DYER, J. H. Equipes que fazem a diferença (Team Building): Estratégias comprovadas para desenvolver equipes de alta performance. São Paulo: Saraiva, 2017.

FLEURY, A. C. C.; FLEURY, M. T. L. Estratégias empresariais e formação de competências: um quebra-cabeça caleidoscópico da indústria brasileira. 3. ed. São Paulo: Atlas, 2004. 
FLEURY, M. T. L.; LACOMBE, B. M. B. A gestão por competência e a gestão de pessoas: um balanço preliminar de resultados de pesquisa no contexto brasileiro. Iberoamerican: Academyof Management International Conference, São Paulo, 2003. Disponível em: www.fgvsp.br/Iberoamerican. Acesso em: i4 Fev. 2022.

GODOY, A. S. Gestão do fator humano: uma visão baseada nos stakeholders. 2. ed. São Paulo: Saraiva, 2008.

KAPLAN, R. S.; NORTON, D. P. Alinhamento: utilizando o balancedscorecard para criar sinergias corporativas. Rio de Janeiro: Campus, 2006.

LOHR, S. The Pandemic Has Accelerated Demands for a More Skilled Work Force. The New York Times, 13.07.2020. Disponível em: https://www.nytimes.com/2020/ 07/13/business/coronavirus-retraining-workers.html. Acesso em: I4 Fev. 2022.

MCCLANAGHAN, K. Can Talent Be Taught? 05.08.2019. Disponível em: https://www.backstage.com/magazine/article/can-talent-taught-238o/. Acesso em: I4 Fev. 2022.

MCKINSEY GLOBAL INSTITUTE. Jobs lost, Jobs gained: what the future of work Will mean for Jobs, skills and wages. 28.11.2017. Disponível em: https://www.mckin sey.com/featured-insights/future-of-work/jobs-lost-jobs-gained-what-the-future-ofwork-will-mean-for-jobs-skills-and-wages. Acesso em: I4 Fev. 2022.

MCKINSEY GLOBAL INSTITUTE. Beyond hiring: How companies are reskilling to address talent gaps. 12.02.2020. Disponível em: https://www.mckinsey.com/busi nessfunctions/people-and-organizational-performance/our-insights/beyond-hiring-howcompanies-are-reskilling-to-address-talent-gaps. Acesso em: i4 Fev. 2022.

MUNCK, L.; BORIM-DE-SOUSA, R. Responsabilidade social empresarial e sustentabilidade organizacional: a hierarquização de caminhos estratégicos para o desenvolvimento sustentável. REBRAE - Revista Brasileira de Estratégia, v. 2, n. 2, p. 185202, 2008.

PRAHALAD, C. K.; HAMEL, G.Competindo pelo futuro: Estratégias inovadoras para obter o controle do seu setor e crier os mercados de amanhã. 19. ed. Rio de Janeiro: Campus, 2005.

RUAS, R. L. Gestão por competências: uma contribuição à estratégia das organizações. In: RUAS, R. L.; ANTONELLO, C. S.; BOFF, L. H. Aprendizagem organizacional e competências: os novos horizontes da gestão. Porto Alegre: Bookman, 2005.

SANT'ANNA, A. S. Profissionais mais competentes, políticas e práticas de gestão mais avançadas? In: PAULA, C. P. A. et al. Administração Contemporânea: desafios e controvérsias. Pedro Leopoldo: Tavares Editora, 2009.

SENGE, P. A Quinta Disciplina: estratégias e ferramentas para construir uma organização que aprende. Rio de Janeiro: Qualitymark, 1997. 
TERRA, E. Carreiras Exponenciais: torne-se o protagonista da sua própria jornada profissional e multiplique suas oportunidades na Era digital. Rio de Janeiro: Alta Books, 202I.

XENIKOU, A. Transformational Leadership, Transactional Contingent Reward, and Organizational Identification: The Mediating Effect of Perceived Innovation and Goal Culture Orientations. Frontiers in Psychology, v. 8, n. 1754, p. I-13, oct., 2017.

WOLFF, L.; CABRAL, P. M. F.; LOURENÇO, P. R. M. R. S. O papel da Liderança na Eficácia de Equipes de Trabalho. Revista Gestão \& Tecnologia, Pedro Leopoldo, v. I3, n. I, p. 177-204, jan./abr. 2013 .

ZARIFIAN, P. Objetivo da competência. São Paulo: Atlas, 2008. 